Research Article

\title{
Significance of Detection of the HER2 Gene and PD-1/PD-L1 in Gastric Cancer
}

\author{
Tian Yun (D), ${ }^{1}$ Sunan Wang, ${ }^{2}$ Bo Jiang, ${ }^{3}$ Changsong Wang, ${ }^{1}$ Nianlong Meng, ${ }^{1}$ Xutao Yuan, ${ }^{1}$ \\ and Yangkun Wang $\mathbb{D}^{4}$
}

${ }^{1}$ People's Liberation Army Joint Logistic Support Force 989th Hospital, LuoYang, Henan 471031, China

${ }^{2}$ ShenZhen Polytechnic, ShenZhen 518110, China

${ }^{3}$ People's Liberation Army Joint Logistic Support Force 990th Hospital, ZhuMaDian, Henan 463000, China

${ }^{4}$ Department of Pathology, ShenZhen Hospital, Southern Medical University, ShenZhen 518110, China

Correspondence should be addressed to Yangkun Wang; dr.wyk@163.com

Received 7 June 2020; Revised 5 August 2020; Accepted 29 September 2020; Published 15 October 2020

Academic Editor: Simona Gurzu

Copyright (C) 2020 Tian Yun et al. This is an open access article distributed under the Creative Commons Attribution License, which permits unrestricted use, distribution, and reproduction in any medium, provided the original work is properly cited.

\begin{abstract}
Objective. To explore the relationship between the HER2 gene and PD-1/PD-L1 in gastric cancer and its significance. Methods. Immunohistochemistry (IHC) and fluorescence in situ hybridization (FISH) were used to detect HER2 protein expression, HER2 gene amplification, and PD-1/PD-L1 expression in 78 cases of gastric cancer. Results. The expression rate of HER2 protein was 43.6\% (34/78), of which 19.4\% (14/78) were HER2 3+, 14.1\% (11/78) were HER2 2+, and 11.5\% (9/78) were HER2 1+. The results showed that $19.2 \%(15 / 78)$ of samples had HER2 gene amplification, 3.8\% (3/78) of samples had a HER2/CEP17 ratio <2.0, and 19.2\% (15/78) of samples had HER2 gene amplificationf and HER2 copy/cell $\geq 6.0$, as detected by FISH. The positive rate of PD-L1 was $38.5 \%$ (30/78) in gastric cancer cells and 50.0\% (39/78) in interstitial lymphocytes. The expression of the HER2 gene, PD-L1, and PD-1 in gastric cancer was correlated with the stage and lymph node metastasis of gastric cancer $(P<0.05)$. Conclusions. The combined detection of the HER2 gene and PD-1/PD-L1 in gastric cancer provides an important reference index for the prognosis of gastric cancer and the benefit of targeted antitumor drugs.
\end{abstract}

\section{Introduction}

Although the incidence of gastric cancer (GC) has fallen significantly in the United States and across the world over the past few decades, it still remains the fifth most common malignancy and the third leading cause of cancer death $[1,2]$. There are approximately 900,000 new cases of GC per year and 723,000 registered deaths worldwide. Most patients with gastric cancer have reached the middle and late stages at the time of diagnosis. Even if perioperative chemotherapy or adjuvant chemotherapy is used, the survival rate of these patients is still low $[3,4]$. Therefore, the search for new therapeutic approaches, such as molecular targeted therapy, has become a hot topic in gastric cancer research. The human epidermal growth factor receptor type 2 (HER2, also referred to as HER2/neu) gene is located on chromosome $17 \mathrm{q} 2 \mathrm{l}$ and encodes a transmembrane tyrosine kinase receptor with a relative molecular weight of $185000 \mathrm{Da}$. At present, the probes for the detection of HER2 gene status are mostly double probes containing the HER2 gene and the centromeric region of chromosome 17 (CEP17), where the gene is located. It was found that HER2 protein was expressed in breast cancer, ovarian cancer, gastric cancer, and other cancers [5-7]. The inducing factors of gastric cancer are mainly related to the activation of carcinogenic factors and the deactivation of tumor suppressor factors. Meanwhile, the tumor cells' immune escape is accompanied by the apoptosis reaction, in which the coregulatory system is involved.

At present, emerging immunotherapy against the programmed death-1 (PD-1)/PD-1 ligand (PD-L) pathway is attracting much attention. The immune escape mechanism of the PD-1/PD-L1 pathway is that the combination of PD$\mathrm{L} 1$ on the surface of tumor cells and PD-1 on the surface of 
T lymphocytes inhibits the activity of T cells so that tumor cells escape from the attack of T lymphocytes [8-10]. PD-1/ PD-L1 immunotherapy aims to treat many kinds of tumors by blocking the PD-1/PD-L1 signaling pathway and restoring the human autoimmune system. Monoclonal antibodies against blocking the PD-1/PD-L1 pathway have entered the clinical stage, and it has been indicated that the therapeutic effect of gastric cancer is significant $[11,12]$. In this paper, immunohistochemistry and fluorescence in situ hybridization (FISH) were used to detect HER2 gene amplification and expression of PD-L1 and PD-1 in gastric cancer tissue and to explore the target and correlation of antitumor drug therapy for gastric cancer to provide help for the prognosis and targeted antitumor drug therapy of gastric cancer.

\section{Materials and Methods}

2.1. Gastric Cancer Tissue Specimen Selection. From November 2015 to February 2019, 78 cases of radical gastrectomy specimens were collected from the Department of Pathology of 989 Hospital, 990 Hospital, and Shenzhen Hospital of Southern Medical University. There were 12 cases of papillary adenocarcinoma, 23 cases of tubular adenocarcinoma, 11 cases of mucinous adenocarcinoma, 7 cases of poorly cohesive carcinoma, and 25 cases of mixed adenocarcinoma. The average age was 57.4 years.

All surgical specimens were processed by pathologists. Specimens were fixed within 30 minutes after surgery and fixed with $10 \%$ neutral buffered formalin (NBF) for 8-48 hours. The volume ratio of the fixative to tissue was $10: 1$. Four to six specimens were cut from the central area, and the surrounding area of the tumor (the proximal and distal margin of the tumor, the tumor, and the adjacent gastric mucosa were not included), one at the deepest infiltrating point and one at the closest serosa layer, and all lymph nodes and cancer nodes were cut in different areas. Hematoxylineosin (HE) staining, immunohistochemistry, and gene detection were performed.

2.2. Immunohistochemistry (IHC). Monoclonal antibodies of PD-L1 (ab230369), PD1 (ab230369), and HER2 (3b5, ab16901) were bought from Abcam company. Using the Envision method, the operation steps were performed strictly in accordance with the product manual, PBS was used as the negative control instead of the primary antibody, and placental villi and lymph nodes were used as the positive controls for PD-L1 and PD-1, respectively. The ready-to-use kit and the primary antibody were purchased from Fuzhou MaiXin Company.

The percentage of tumor cells exhibiting cell-surface staining for PD-L1 was scored by two independent pathologists who were unaware of outcomes. First, the tumor cell area was determined under $4 \times$ low-power microscope; then, under 10-40× microscope, the nuclear staining site of PD-L1 and the percentage of PD-L1 positive tumor cells were identified. Tumor cells with $\geq 5 \%$ positive localization of PD-L1 in the cell membrane and/or cytoplasm were considered positive, and tumor stromal cells with $\geq 5 \%$ positive localization of PD-1 in the cell membrane and/or cytoplasm were considered positive $[9,13]$. HER2 positive results were considered as follows: The positive localization was on the cell membrane. There was no staining on the cell membrane, and the result was 0 ; if tumor cells were faint in membrane staining, the result was 1+; if the basement membrane, side membrane, or integrity membrane of tumor cells had weak to moderate staining, the result was 2+; if there was strong positive staining on basement membrane, side membrane, or integrity membrane of tumor cells, the result was $3+$. The positive staining area was evaluated as follows: if the membrane of tumor cells had no staining, the sample was considered negative; if $\geq 80 \%$ of cells were stained, the sample was considered extensive type; if $21 \%$ $79 \%$ of cells were stained, the sample was considered partial type; and if $\leq 20 \%$ of cells were stained, the sample was considered focal type. Two pathologists were employed to read the film.

2.3. Fluorescence In Situ Hybridization. Paraffin Pretreatment Kit II (mainly including pretreatment solution and protease solution) and the Path Vysion TM HER2 Probe Kit were purchased from Vysis. The pretreatment procedure and FISH procedure of paraffin-embedded gastric cancer tissue sections were carried out in accordance with the literature $[14,15]$ and the instructions on the kit.

The gastric cancers with IHC grade HER 2+ results underwent FISH analysis. First, the positive area of gastric adenocarcinoma cells was confirmed on IHC, and then, the same field of view from IHC stain was assessed by FISH under a $10 \times$ objective lens, and the whole section was observed under $40 \times$ objective lens. More than $75 \%$ of the cancer cell nuclei had a hybridization signal, which was regarded as a satisfactory result; the lens was replaced with a $100 \times$ objective lens to count at least 30 cancer cells with complete boundaries, isolated and nonoverlapping. The evaluation criteria for HER2 gene amplification were as follows: HER2/CEP17 ratio $\geq 2.0$, and average HER2 copies/ cells $\geq 4.0$ : FISH positive; HER2/CEP17 ratio $<2.0$, average HER2 copies/cells <4.0: FISH negative. If the ratio of HER2/ CEP17 was less than 2.0 and the average copy number/cell of HER2 was more than 4.0 and less than 6.0, the signals in at least 20 nuclei were counted again. If the results changed, the two results were comprehensively judged and analyzed. In this group, if the ratio of HER2/CEP17 was less than 2.0 and the average copy number of HER2/cell was more than 6.0, the sample was judged as FISH positive (referred to as high multibody cell for short). If many HER2 signals were connected into clusters, they were directly judged as FISH positive. This group was divided into cluster amplification, large granular amplification, and dot amplification.

2.4. Statistical Analysis. SPSS 22.0 software was used for statistical analysis of all data. The $\chi 2$ test was used to analyze the relationship between the expression of HER2, PD-1, and PD-L1 and the clinicopathological characteristics of gastric cancer. The correlation between the two methods was 
analyzed by Pearson correlation analysis, and $P<0.05$ was considered statistically significant.

\section{Results}

3.1. Relationship between HER2 Gene Amplification and the Protein Expression Rate. HER2 protein was positively expressed in the cell membrane. In our search, the positive expression rate was $43.6 \%(34 / 78)$, in which the expression of HER2 protein $3+$ accounted for 19.4\% (14/78), including 8 cases of $3+$ extensive staining (Figure 1(a)), 4 cases of partial staining (Figure 1(b)), and 2 cases of focal staining (Figure 1(c)); the expression of HER2 protein $2+$ accounted for $14.1 \%$ (11/78), including 8 cases of $2+$ extensive staining, 2 cases of partial staining, and 1 case of focal staining; the expression of HER2 protein 1+ accounted for $11.5 \%$ (9/78), including 7 cases of $1+$ extensive type, 1 case of partial type, and 1 case of focal type. Forty-four cases were negative, accounting for $56.4 \%$ (44/78) of all cases. The amplification rate of the HER2 gene was $19.2 \%$ (15/78) by FISH technology, including 3 cases of HER2 gene cluster amplification (Figure 2(a)), 5 cases of large granule amplification (Figure 2(b)), 4 cases of dot amplification (Figure 2(c)), and 3 cases of high polymorph amplification (Figure 2(d)). The relationship between HER2 gene protein expression and HER2 gene amplification in gastric cancer is shown in Table 1.

3.2. Relationship of $P D-1 / P D-L 1$ Expression. The expression of PD-L1-positive cells in gastric cancer was multifocal and flaky (Figure 3); exfoliated cancer cells in the glandular cavity were expressed in different degrees. The total positive rate was $38.5 \%$ (30/78); $\mathrm{PD}-1$ positive cells in tumor stroma were scattered or clumped: they were mainly located in the area of lymphocyte aggregation with focal distribution between adenocarcinoma cells and in the area of single lymphocyte between gastric adenocarcinoma cells (Figure 4). The total positive rate was 50.0\% (39/78). The difference of PD-1/PD-L1 expression in tumor cells and tumor stroma was statistically significant $(P<0.05)$, and it was correlated with gastric cancer stage and lymph node metastasis $(P<0.05)$.

\subsection{HER2 Gene Amplification and PD-1/PD-L1 Expression} and Their Relationship with Clinicopathological Parameters. The amplification rate of the HER2 gene and the expression of PD-1/PD-L1 were not related to the sex and age of patients $(P>0.05)$; the amplification rate of the HER2 gene and the expression of $\mathrm{PD}-1 / \mathrm{PD}-\mathrm{L} 1$ were related to the depth of invasion and lymph node metastasis of gastric cancer, with significant differences $(P<0.05)$, as shown in Table 2 .

\section{Discussion}

The status of the HER2 gene determines the benefit of targeted treatment for gastric/GEJ adenocarcinoma. Therefore, accurate detection of the HER2 gene is very important for the selection of patients for targeted treatment. At present, detection of the HER2 gene in gastric/GEJ adenocarcinoma has become a routine project in the pathology department, and many countries have formulated HER2 detection guidelines [16, 17]. The detection of HER2 in gastric cancer is different from that in breast cancer, which has a wide range of morphological heterogeneities. The detection results are affected by many factors, as well as the quality control of the laboratory and the interpretation of staining results. Some studies indicated that the expression rate of HER2 protein was significantly different from $6 \%$ to $34 \%$ [18-21]. In our research, HER2 protein was detected by combining the positive intensity and the positive area, which was divided into extensive staining, partial staining, and focal staining. The total positive expression rate of HER2 protein was $43.6 \%$ (34/78), of which HER2 protein $3+$ expression accounted for $19.4 \%$ (14/78), including 8 cases of $3+$ extensive staining, 4 cases of partial staining, and 2 cases of focal staining; HER2 protein $2+$ expression accounted for $14.1 \%$ (11/78), including 8 cases of $2+$ extensive staining, 2 cases of partial staining, and 1 case of focal staining; HER2 protein $1+$ expression accounted for $11.5 \%$ (9/78), including 7 cases of $1+$ extensive staining, 1 case of partial staining, and 1 case of focal staining. Forty-four cases were negative, accounting for $56.4 \%$ (44/78) of all cases. The amplification rate of the HER2 gene was $19.2 \%$ (15/78), as detected by the FISH technique; amplifications included 3 cases of HER2 gene cluster amplification, 5 cases of large granule amplification, 4 cases of dot amplification, and 3 cases of high polymorph amplification. The results showed that HER2 amplification was correlated with gastric cancer stage and lymph node metastasis $(P<0.05)$.

There are many reasons for human tumors, which are closely related to the body's autoimmune function. Immunostimulatory molecules have become a hot spot in immunology in recent years. PD-1 and its ligand PD-L1 play an important role in tumor progression. PD-1 is a type I transmembrane protein composed of 288 amino acids, and $\mathrm{PD}-\mathrm{L} 1$ is a type I transmembrane protein composed of 290 amino acids [11]. PD-1 binds to PD-L1 through the IGV domain of the extracellular domain. PD-1 is expressed on the surface of T cells, B cells, natural killer cells, and tumor infiltrating lymphocytes. PD-L1 is widely expressed in tumor cells. PD-L1 induces the binding of PD-1 on the surface of T-lymphocytes to transmit inhibitory signals to $\mathrm{T}$ cells, which inactivates $\mathrm{T}$ lymphocytes and suppresses the antitumor immune response [12]. Therefore, blocking the PD-1/ PD-L1 pathway with drugs can enhance the function of $T$ cells and cause tumor cell death, which will open a new window for tumor treatment. The expression of PD-1/PDL1 in lung cancer, breast cancer, and malignant melanoma is higher than that in gastric cancer. The positive rate of PD-L1 expression in [13] tumor cells was $23.87 \%$. The positive rate of PD-1 expression was $53.76 \%$. PD-L1 was not expressed in normal gastric tissues but was detected in $42 \%$ of gastric cancer tissues. The positive rates of PD-L1 and PD-1 expression in gastric cancer cells were $38.5 \%$ and $50.0 \%$, respectively. This study found that the expression of PD-1/PDL1 was not related to the age of patients with gastric cancer but was related to the stage, lymph node metastasis, and prognosis of gastric cancer. 

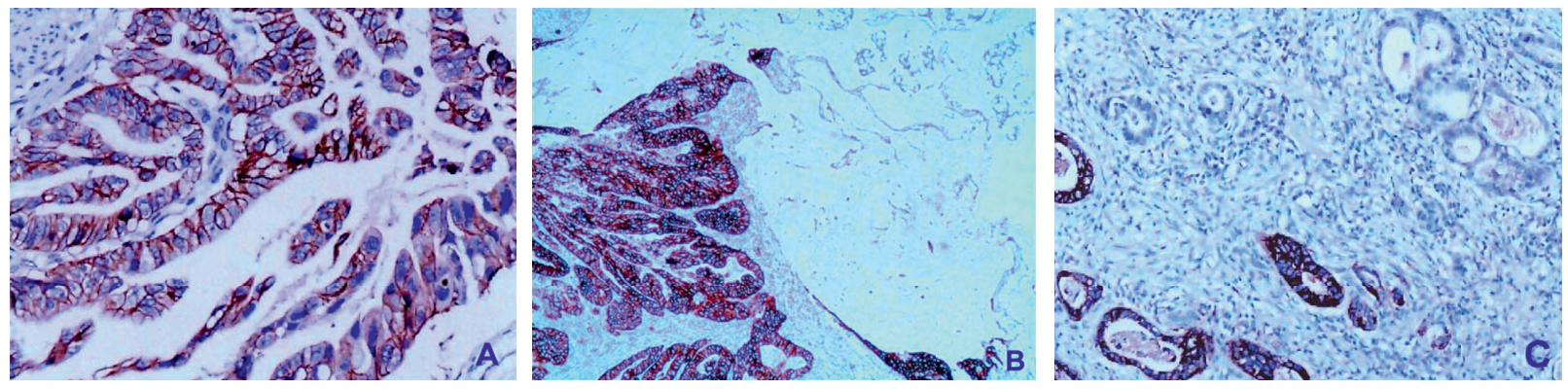

FIGURE 1: (a) Gastric papillary adenocarcinoma, HER2 positive 3+ extensive staining (X200); (b) Gastric mixed adenocarcinoma, mucinous adenocarcinoma, and papillary adenocarcinoma, HER2 positive 3+ partial staining (X40); (c) gastric tubular papillary adenocarcinoma, HER2 positive 3+ focal staining (X200), Envision method.
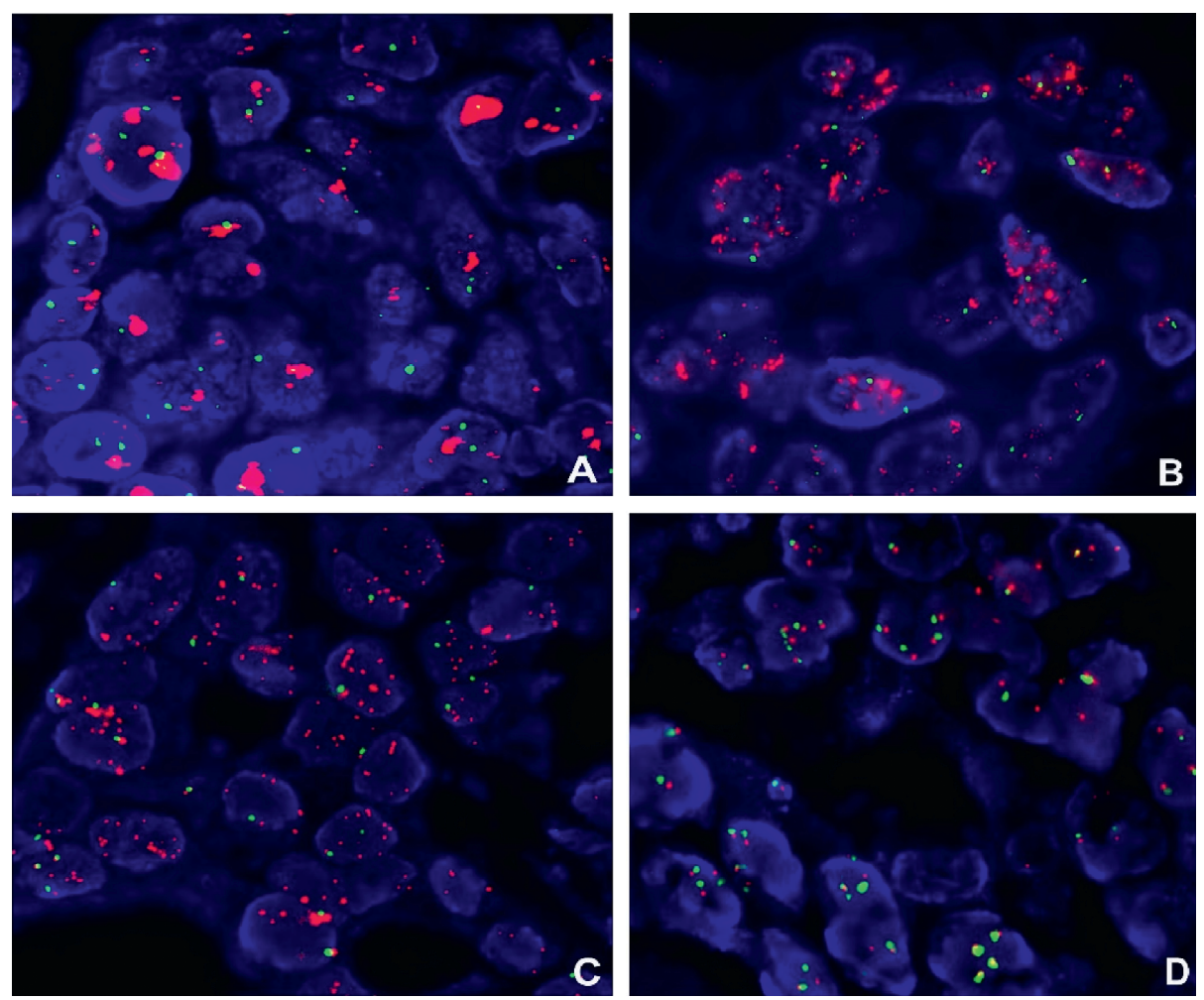

FIGURE 2: FISH method to detect HER2 gene amplification, red as probe signal, green as chromosome 17: (a) HER2 gene cluster amplification; (b) HER2 gene large particle amplification; (c) HER2 gene dot amplification; (d) HER2 gene high polymorph amplification.

TABLE 1: Comparison of HER2 protein expression and HER2 gene amplification in 78 cases of gastric cancer.

\begin{tabular}{lcc}
\hline & HER2 protein expression rate (\%) & Amplification rate of HER2 gene (\%) \\
\hline- & $44 / 78(56.4)$ & 0 \\
+ & $9 / 78(11.5)$ & 0 \\
++ & $11 / 78(14.1)$ & $1 / 11(9.1)$ \\
+++ & $14 / 78(19.4)$ & $14 / 14(100.0)$ \\
Total & $34 / 78(43.6)$ & $15 / 78(19.2)$ \\
\hline
\end{tabular}

In recent years, it was reported that the status of the HER2 gene in gastric cancer is related to the expression of p53 protein and the number of Ki67-positive cells in cell proliferation $[22,23]$. In this study, we found that HER2 gene status was related to gastric cancer stage, lymph node metastasis, and prognosis, which was consistent with the literature. The PD-1/PD-L1 pathway is an important mechanism of immunosuppression in the tumor microenvironment. Drugs are used to block this pathway and enhance immune function. By detecting the expression of PD$1 / \mathrm{PD}-\mathrm{L} 1$ in gastric cancer, we can evaluate the prognosis of patients and provide some basis for immunotherapy of 

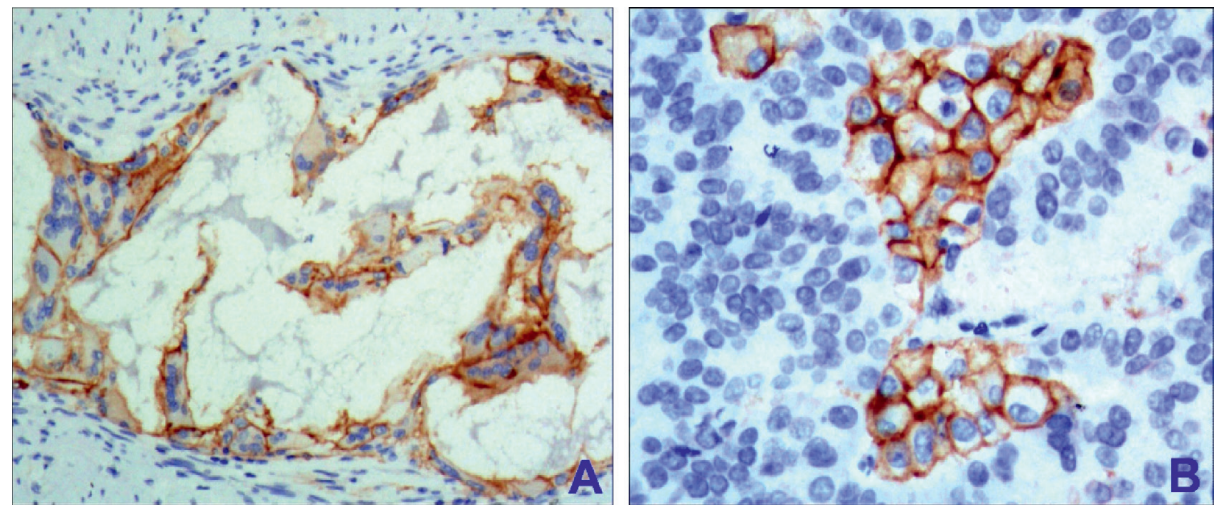

Figure 3: Gastric adenocarcinoma. (a) Gastric mucinous adenocarcinoma shows positive PD-L1 expression (X200). (b) Poorly differentiated gastric adenocarcinoma shows positive PD-L1 expression (X200), Envision method.
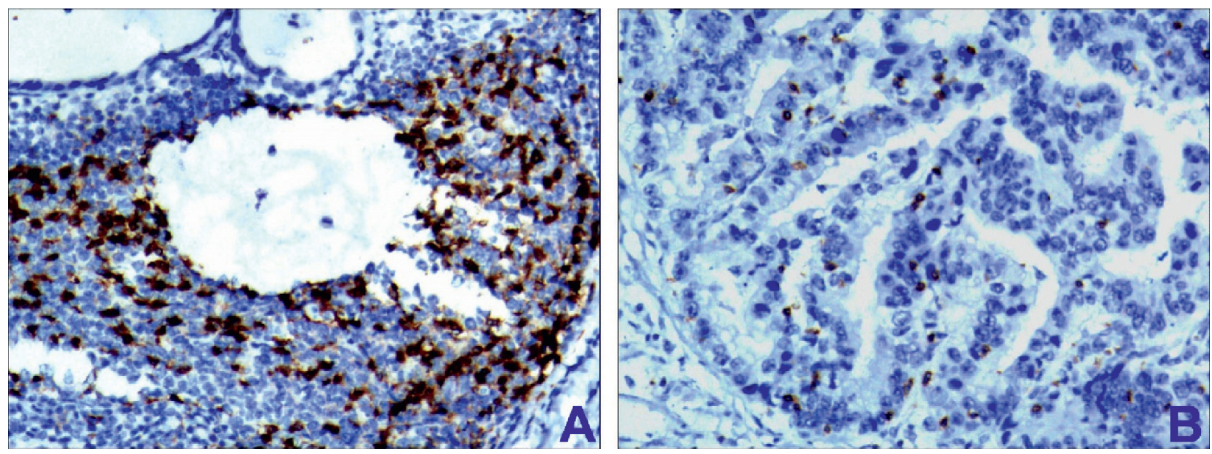

FIGURE 4: Gastric adenocarcinoma. (a) Interstitial lymphocytes of mucinous adenocarcinoma show positive expression of PD-1 (X200). (b) Interstitial lymphocytes of papillary gastric adenocarcinoma show negative expression of PD-1 (X200), Envision method.

TABLE 2: Relationship between HER2 gene amplification and PD-1/PD-L1 expression and clinicopathological parameters in 78 cases of gastric cancer.

\begin{tabular}{|c|c|c|c|c|c|c|c|}
\hline Type & $n$ & $\begin{array}{l}\text { HER2 gene } \\
\text { Positive, } \\
\text { negative }\end{array}$ & $\begin{array}{c}P \\
\text { value }\end{array}$ & $\begin{array}{l}\text { Expression of PD-L1 in } \\
\text { tumor cells } \\
\text { Positive, negative }\end{array}$ & $\begin{array}{c}P \\
\text { value }\end{array}$ & $\begin{array}{c}\text { Expression of PD-1 in tumor } \\
\text { stromal lymphocytes } \\
\text { Positive, negative }\end{array}$ & $\begin{array}{c}P \\
\text { value }\end{array}$ \\
\hline \multicolumn{8}{|l|}{ Sex } \\
\hline Male & 53 & $\begin{array}{c}11(26.4), 42 \\
(79.2)\end{array}$ & \multirow{2}{*}{0.619} & $22(41.5), 32(60.4)$ & \multirow{2}{*}{0.516} & 29 (54.7), $24(45.43)$ & \multirow{2}{*}{0.377} \\
\hline Female & 25 & $\begin{array}{c}4(16.0), 21 \\
(84.0)\end{array}$ & & $8(32.0), 17(68.0)$ & & $11(44.0), 14(56.0)$ & \\
\hline \multicolumn{8}{|l|}{ Age } \\
\hline$\leq 60$ & 31 & $\begin{array}{c}6(19.4), 25 \\
(80.0)\end{array}$ & \multirow{2}{*}{0.982} & $9(29.0), 22(70.8)$ & \multirow{2}{*}{0.164} & $13(41.9), 18(58.1)$ & \multirow[b]{2}{*}{0.247} \\
\hline$>60$ & 47 & $\begin{array}{c}9(19.1), 38 \\
(80.9)\end{array}$ & & $21(44.7), 26(55.3)$ & & $26(55.3), 21(44.7)$ & \\
\hline \multicolumn{8}{|l|}{ Histological classification } \\
\hline $\begin{array}{l}\text { Papillary } \\
\text { adenocarcinoma }\end{array}$ & 12 & $\begin{array}{c}3(25.0), 9 \\
\quad(75.0)\end{array}$ & \multirow{5}{*}{0.924} & 5 (41.6), $7(58.3)$ & \multirow{5}{*}{0.991} & $6(50.0), 6(50.0)$ & \multirow{5}{*}{0.977} \\
\hline $\begin{array}{l}\text { Tubular } \\
\text { adenocarcinoma }\end{array}$ & 23 & $\begin{array}{c}5(21.7), 18 \\
(78.3)\end{array}$ & & $9(39.1), 14(60.9)$ & & $11(47.8), 12(52.2)$ & \\
\hline $\begin{array}{l}\text { Mucinous } \\
\text { adenocarcinoma }\end{array}$ & 11 & $\begin{aligned} 1 & (9.1), 10 \\
& (90.0)\end{aligned}$ & & $4(36.4), 7$ (63.6) & & $5(45.5), 6(54.5)$ & \\
\hline Low adhesion cancer & 7 & $\begin{array}{c}1(14.3), 6 \\
(85.7)\end{array}$ & & 2 (28.6), 5 (71.4) & & 3 (42.9), 4 (57.1) & \\
\hline $\begin{array}{l}\text { Mixed } \\
\text { adenocarcinoma } \\
\text { Stage }\end{array}$ & 25 & $\begin{array}{c}5(20.0), 20 \\
(80.0)\end{array}$ & & $10(40.0), 15(60.0)$ & & $14(56.0), 11(44.0)$ & \\
\hline
\end{tabular}


TABle 2: Continued.

\begin{tabular}{|c|c|c|c|c|c|c|c|}
\hline \multirow{2}{*}{ Type } & \multirow{2}{*}{$n$} & \multirow{2}{*}{$\begin{array}{c}\text { HER2 gene } \\
\text { Positive, } \\
\text { negative }\end{array}$} & \multirow{2}{*}{$\begin{array}{c}P \\
\text { value }\end{array}$} & $\begin{array}{l}\text { Expression of PD-L1 in } \\
\text { tumor cells }\end{array}$ & \multirow{2}{*}{$\begin{array}{c}P \\
\text { value }\end{array}$} & $\begin{array}{l}\text { Expression of PD-1 in tumor } \\
\text { stromal lymphocytes }\end{array}$ & \multirow{2}{*}{$\begin{array}{c}P \\
\text { value }\end{array}$} \\
\hline & & & & Positive, negative & & Positive, negative & \\
\hline $\mathrm{T} 1 / \mathrm{T} 2$ & 30 & $\begin{array}{l}2(6.7), 28 \\
\quad(93.3)\end{array}$ & \multirow{2}{*}{0.026} & $8(26.7), 22(73.3)$ & \multirow{2}{*}{0.129} & $9(30.0), 21(70.0)$ & \multirow{2}{*}{0.005} \\
\hline $\mathrm{T} 3 / \mathrm{T} 4$ & 48 & $\begin{array}{c}10(20.8), 38 \\
(79.2)\end{array}$ & & $21(43.8), 27(56.3)$ & & $30(62.5), 21(37.5)$ & \\
\hline \multicolumn{8}{|c|}{ Lymph node metastasis } \\
\hline With & 56 & $\begin{array}{c}12(21.4), 44 \\
(78.6)\end{array}$ & \multirow{2}{*}{0.787} & $26(43.4), 30(53.6)$ & \multirow{2}{*}{0.021} & $32(58.2), 23(41.8)$ & \multirow{2}{*}{0.037} \\
\hline Without & 22 & $\begin{array}{c}3(13.6), 9 \\
(40.9)\end{array}$ & & $4(18.2), 18(81.8)$ & & $7(31.8), 15(68.2)$ & \\
\hline
\end{tabular}

gastric cancer. It was also found that the detection of the HER2 gene and PD-1/PD-L1 in gastric cancer was related to gastric cancer stage and lymph node metastasis $(P<0.05)$.

In conclusion, HER2 protein is heterogeneous in gastric cancer, and the criterion and refinement of the HER2 test is the guarantee of correct medication guidance. This study emphasizes the intensity and scope of HER2 detection. HER2 protein expression can be divided into extensive staining, partial type, and focal staining. HER2 gene expression can be divided into cluster staining, large granule staining, dot staining, and high pleomorphism, which helps clinicians grasp the results of detection strategy, guide drug use, and predict prognosis. The PD-1/PD-L pathway is an important mechanism of immunosuppression in the tumor microenvironment. Drugs are used to block this pathway and enhance immune function. In this study, the HER2 gene and PD-1/PD-L1 were jointly detected in gastric cancer. All three genes were related to gastric cancer stage and lymph node metastasis $(P<0.05)$. This conclusion provides an important reference for the prognosis of gastric cancer and the benefit of targeted antitumor drugs.

\section{Data Availability}

All the data generated or analyzed during this study are included within this article.

\section{Disclosure}

This work was performed as part of the employment of Tian Yun, Changsong Wang, Nianlong Meng, Xutao Yuan, and Yangkun Wang.

\section{Conflicts of Interest}

The authors declare that they have no conflicts of interest to this work.

\section{References}

[1] P. Guilford, V. Blair, H. More, and B. Humar, "A short guide to hereditary diffuse gastric cancer," Hereditary Cancer in Clinical Practice, vol. 5, no. 4, pp. 183-194, 2007.

[2] Z. Kadar, I. Jung, J. Orlowska et al., "Geographic particularities in incidence and etiopathogenesis of sporadic gastric cancer," Polish Journal of Pathology, vol. 3, no. 3, pp. 254-259, 2015.

[3] S. S. Li, B. V. Udelsman, A. Parikh et al., "Impact of postoperative complication and completion of multimodality therapy on survival in patients undergoing gastrectomy for advanced gastric cancer," Journal of American College of Surgeons, vol. 230, no. 6, pp. 912-924, 2020.

[4] T. C. Felismino, A. C. F. De Oliveira, A. C. F. Alves et al., "Primary tumor location is a predictor of poor prognosis in patients with locally advanced esophagogastric cancer treated with perioperative chemotherapy," Journal of Gastrointestinal Cancer, vol. 51, no. 2, pp. 484-490, 2019.

[5] Y. K. Wang, C. F. Gao, T. Yun et al., "Assessment of ERBB2 and EGFR gene amplification and protein expression in gastric carcinoma by immunohistochemistry and fluorescence in situ hybridization," Molecular Cytogenetics, vol. 4, no. 1, p. 14, 2011.

[6] F. A. Rima, M. Hussain, N. Haque et al., "HER2 status in gastric and gastroesophageal junction adenocarcinoma," Mymensingh Medical Journal: MMJ, vol. 26, no. 2, pp. 372379, 2017.

[7] T. Kijima, T. Arigami, Y. Uenosono et al., "Comparison of HER2 status before and after trastuzumab-based chemotherapy in patients with advanced gastric cancer," Anticancer Research, vol. 40, no. 1, pp. 75-80, 2020.

[8] A. Crescenzi, C. Taffon, M. Donati, M. P. Guarino, S. Valeri, and R. Coppola, "PD-L1/PD-1 check-point in gastric carcinoma with lymphoid stroma case report with immunochemical study," Medicine (Baltimore), vol. 96, no. 7, Article ID e5730, 2017.

[9] R. Saito, H. Abe, A. Kunita, H. Yamashita, Y. Seto, and M. Fukayama, "Overexpression and gene amplification of PDL1 in cancer cells and PD-L1+ immune cells in Epstein-Barr virus-associated gastric cancer: the prognostic implications," Modern Pathology, vol. 30, no. 3, pp. 427-439, 2017.

[10] C. Böger, H.-M. Behrens, M. Mathiak, S. Krüger, H. Kalthoff, and C. Röcken, "PD-L1 is an independent prognostic predictor in gastric cancer of western patients," Oncotarget, vol. 7, no. 17, pp. 24269-24283, 2016.

[11] P. N. Tran, S. Sarkissian, J. Chao, and S. J. Klempner, "PD-1 and PD-L1 as emerging therapeutic targets in gastric cancer: current evidence," Gastrointestinal Cancer: Targets and Therapy, vol. 7, pp. 1-11, 2017.

[12] B. J. Noh, J. H. Kim, and D. W. Eom, "Prognostic significance of categorizing gastric carcinoma by PD-L1 expression and tumor infiltrating lymphocytes," Annals of Clinical and Laboratory Science, vol. 48, no. 6, pp. 695-706, 2018. 
[13] H. Saito, Y. Kono, Y. Murakami et al., "Highly activated PD-1/ PD-L1 pathway in gastric cancer with PD-L1 expression," Anticancer Research, vol. 38, no. 1, pp. 107-112, 2018.

[14] Y.-K. Wang, Z. Chen, T. Yun et al., "Human epidermal growth factor receptor 2 expression in mixed gastric carcinoma," World Journal of Gastroenterology, vol. 21, no. 15, pp. 4680-4687, 2015.

[15] S. Wang, Y. Li, Z. Xu et al., "Study on the protein expression and amplification of HER2 gene in gastric cancer," Oncology and Translational Medicine, vol. 13, no. 6, pp. 267-272, 2014.

[16] D. Subasinghe, N. Acott, and M. P. Kumarasinghe, "A survival guide to HER2 testing in gastric/gastroesophageal junction carcinoma," Gastrointestinal Endoscopy, vol. 90, no. 1, pp. 44-54, 2019.

[17] J. Zheng, D. Lin, J. Ji et al., "HER2 gene detection of gastric cancer 2016 edition," Chinese Journal of Pathology, vol. 45, no. 8 , pp. 528-531, 2016.

[18] A. Ilhan-Mutlu, H. Taghizadeh, A. Beer et al., "Correlation of trastuzumab-based treatment with clinical characteristics and prognosis in HER2-positive gastric and gastroesophageal junction cancer: a retrospective single center analysis," Cancer Biology \& Therapy, vol. 19, no. 3, pp. 169-174, 2018.

[19] F. Berlth and A. H. Hoelscher, "History of esophagogastric junction cancer treatment and current surgical management in western countries," Journal of Gastric Cancer, vol. 19, no. 2, pp. 139-147, 2019.

[20] S. Mitani and H. Kawakami, "Emerging targeted therapies for HER2 positive gastric cancer that can overcome trastuzumab resistance," Cancers (Basel), vol. 12, no. 2, p. 400, 2020.

[21] C. Dominguez, M. Rosa, T. B. George, J. Pimiento, G. Y. Lauwers, and D. Coppola, "Evaluation of expression of human epidermal growth factor receptor 2 (HER2) in gastric and gastroesophageal junction adenocarcinoma using IHC and dual-ISH," Anticancer Research, vol. 38, no. 1, pp. 367-372, 2018.

[22] Y.-K. Wang, C.-F. Gao, X. W. Zhang et al., "Use of FISH in detection of HER2 gene and its relationship with p53 protein expression in gastric carcinoma," Chinese Journal of Clinical and Experimental Pathology, vol. 27, no. 2, pp. 126-129, 2011.

[23] D. M. Badary, M. E. Abdel-Wanis, M. Z. Hafez, and N. A. Aboulhagag, "Immunohistochemical analysis of PTEN, HER2/neu, and ki67 expression in patients with gastric cancer and their association with survival," Pathophysiology, vol. 24, no. 2, pp. 99-106, 2017. 